\title{
Modelling of snow entrainment and deposition in powder-snow avalanches
}

\author{
Dieter Issler \\ Swiss Federal Institute for Snow and Avalanche Research, CH-7260 Davos Dorf, Switzerland
}

\begin{abstract}
Following Norem's description of powder-snow avalanche formation and structure, we propose a mathematical model that consists of a suspension layer and a socalled saltation layer. The latter is only a few meters deep and is modelled by depth-averaged mass and momentum balances. In the suspension layer, the mass- and momentumbalance equations for the mixture are supplemented by the snow mass balance and the transport equations for turbulent kinetic energy and dissipation. Mass and momentum exchange between the two layers is determined by particle settling, turbulent diffusion against the concentration gradient and aerodynamic shear forces. The net erosion or deposition rate is a function of the kinetic energy of the impacting particles. The saltation layer reacts on the suspension layer in that saltating particles extract momentum from the air flow. The preliminary estimates of the model parameters can be refined by means of saltation-trajectory simulations. Three-dimensional simulations with a simplified model have clearly shown the importance of snow erosion and deposition in practical applications. This approach is well suited for coupling to a dense-flow avalanche model.
\end{abstract}

\section{INTRODUCTION: THE MAIN PHYSICAL PRO- CESSES IN POWDER-SNOW AVALANCHES}

Powder-snow avalanches (PSAs) tend to assume a mythical aura in people's minds due to their often enormous size, high speed and resulting large devastated areas. On the practical side, true PSAs are a relatively rare phenomenon and only a modest fraction of avalanche damage is caused by them. Nevertheless, avalanche-hazard mapping in mountainous areas needs to take into account PSA effects. In view of the demand for reliable estimates of PSA trajectories and pressures, several models of different degrees of sophistication have been developed over the past few years (Fukushima and Parker, 1990; Brandstätter and others, 1992; Hermann and others, 1994, 1995; Rapin, 1995; Naaim, 1995). Many of them draw heavily on earlier work that has already been reviewed by Scheiwiller and Hutter (1982) and Hutter (1995).

Two shortcomings appear to be shared by all the PSA models in use today: (i) the formation of the PSA from a dense-flow avalanche (DFA) and their subsequent interaction are not modelled; (ii) snow entrainment and deposition - two decisive effects - are completely neglected or incorporated through ad hoc assumptions. In order to address the second point and open the door to dealing with the first, we adopt the picture of PSA structure and formation proposed by Norem (1995) on the basis of observations (Schaerer and Salway, 1980; Norem and others, 1985; Nishimura and others, 1993; Issler and others, 1996), the similarity with snowdrift and a qualitative analysis of shear stresses. A physical description of snow entrainment and deposition is obtained and rough estimates of the model parameters can be given. Straightforward modifications to be described elsewhere will allow coupling to a DFA model.
The main assumptions in the present model are the following:

1. The PSA can approximately be described in terms of a so-called saltation layer with a density in the range $20-50 \mathrm{~kg} \mathrm{~m}^{-3}$ and a suspension layer (the powder-snow "cloud") of lower density $\left(1-10 \mathrm{~kg} \mathrm{~m}^{-3}\right)$.

2. Snow particles in the saltation layer eject other particles when they hit the snow cover (or DFA surface). This is assumed to be the dominant factor for the mass balance and ground friction of the PSA. The yield (number of ejected particles per landing particle) is taken to be a slowly varying function of the impact energy.

3. The depth of the saltation layer is determined by the average slope-perpendicular velocity imparted to ejected particles, which is assumed to be a fixed fraction of the average landing velocity.

4. Mass exchange between the saltation and suspension layers is due to the turbulence at the bottom of the suspension layer and settling of particles under gravity.

5. Momentum exchange between the saltation and suspension layers is due to drag on the saltating particles as well as to mass exchange.

\section{THE SUSPENSION LAYER}

In the following, the subscripts $\mathrm{f}$ and $\mathrm{p}$ stand for the fluid (air) and the particles (snow), respectively. Their effective densities, $\rho_{\mathrm{f}, \mathrm{p}}$, and the mixture density, $\rho$, are expressed in 
terms of the intrinsic densities, $\hat{\rho}_{\mathrm{f}, \mathrm{p}}$ and the volumetric particle concentration $c$. Setting $R \equiv\left(\hat{\rho}_{\mathrm{p}}-\hat{\rho}_{\mathrm{f}}\right) / \hat{\rho}_{\mathrm{f}}$, one finds

$$
\begin{gathered}
\rho_{\mathrm{f}}=(1-c) \hat{\rho}_{\mathrm{f}}, \quad \rho_{\mathrm{p}}=c \hat{\rho}_{\mathrm{p}} ; \\
\rho=\rho_{\mathrm{f}}+\rho_{\mathrm{p}}=\hat{\rho}_{\mathrm{f}}(1+R c) .
\end{gathered}
$$

The mixture velocity is defined in terms of the fluid and particle velocities and densities by $\mathbf{U} \equiv\left(\rho_{\mathrm{f}} \mathbf{U}_{\mathrm{f}}+\rho_{\mathrm{p}} \mathbf{U}_{\mathrm{p}}\right) / \rho$. The Stokes number - the ratio of the particle relaxation time and the typical flow time-scale, $\mathrm{St} \equiv t_{\mathrm{p}} / t_{\mathrm{f}}$ - is relatively low at $0.1-1$. Therefore, we approximate the relative velocity between phases, $\mathbf{u} \equiv \mathbf{U}_{\mathrm{p}}-\mathbf{U}_{\mathrm{f}}$, by the average settling velocity of the particles, $w_{\mathrm{s}} \equiv\left|w_{\mathrm{s}}\right| \approx 0.5-2 \mathrm{~m} \mathrm{~s}^{-1}$.

Given the high Reynolds numbers $\operatorname{Re}=\mathcal{O}\left(10^{8}\right)$ of PSAs, some form of turbulence modelling is required. To this end, fields are split into mean and fluctuation components, $\Phi(\mathbf{x}, t)=\bar{\Phi}(\mathbf{x}, t)+\Phi^{\prime}(\mathbf{x}, t)$. For the mixture velocity, Favre-averaging is used: $\mathbf{U}(\mathbf{x}, t)=\widetilde{\mathbf{U}}(\mathbf{x}, t)+\mathbf{U}^{\prime \prime}(\mathbf{x}, t)$ with $\widetilde{\mathbf{U}}(\mathbf{x}, t) \equiv \overline{\rho \mathbf{U}} / \bar{\rho}$.

The equations generally contain terms with correlations of two or more fluctuation fields. Invoking the eddy-viscosity and eddy-diffusivity concepts, we set

$$
-\overline{\mathbf{U}^{\prime \prime} \mathbf{U}^{\prime \prime}} \approx \nu_{\mathrm{t}}\left(\nabla \tilde{\mathbf{U}}+(\nabla \tilde{\mathbf{U}})^{\mathrm{T}}\right) \quad \text { and }-\overline{c^{\prime} \mathbf{U}^{\prime \prime}} \approx \frac{\nu_{\mathrm{t}}}{\sigma_{\mathrm{c}}} \nabla \bar{c} ;
$$

in approximations (2), higher-order correlations that are expected to be small have been neglected. The Prandtl numbers $\sigma_{c}$ etc. characterize the transport properties of the respective quantities $c, \ldots$ under turbulent velocity fluctuations. The turbulent viscosity is modelled as

$$
\nu_{\mathrm{t}}=l_{\mathrm{m}} v_{\mathrm{m}}=c_{\mu} \frac{\tilde{k}^{2}}{\tilde{\epsilon}} .
$$

Prandtl's mixing length and mixing velocity, $l_{\mathrm{m}} \propto \tilde{k}^{\frac{3}{2}} \tilde{\epsilon}^{-1}$ and $v_{\mathrm{m}} \propto \tilde{k}^{\frac{1}{2}}$, are expressed in terms of the (Favre-averaged) turbulent kinetic energy, $\tilde{k}=\overline{\rho k_{\text {turb }}} / \bar{\rho}$, where

$$
k_{\text {turb. }}=\frac{1}{2} \mathbf{U}^{\prime \prime 2}=\frac{1}{2}\left(U^{\prime \prime 2}+V^{\prime \prime 2}+W^{\prime \prime 2}\right)
$$

and the turbulent-dissipation rate, $\tilde{\epsilon}=\overline{\rho \epsilon} / \bar{\rho} . c_{\mu} \approx 0.09$ is an empirical constant.

Henceforth, suppressing overlines and tildes, the balance equations for air and particle mass can be expressed as the mixture mass balance and the transport equation for the concentration field,

$$
\left.\partial_{\mathrm{t}} \rho+\nabla \cdot \mathbf{U} \rho\right)=0,
$$

$\partial_{\mathrm{t}} c+\nabla \cdot(\mathbf{U} c)=-w_{\mathrm{s}} \cdot \nabla\left(\frac{c}{1+R c}\right)+\nabla \cdot\left(\frac{\nu_{t} / \sigma_{c}}{1+R c} \nabla c\right)$

The righthand side of Equation (6) describes settling and turbulent diffusion of particles with respect to the barycentric velocity field. Due to variable particle concentration, the latter is not divergence-free even though we consider the air as incompressible. Combining Equations (5), (6) and (1), we obtain

$$
\nabla \cdot \mathbf{U}=w_{\mathrm{s}} \cdot \nabla\left(\frac{R c}{1+R c}\right)-\nabla \cdot\left(\frac{R \nu_{\mathrm{t}} / \sigma_{\mathrm{c}}}{1+R c} \nabla c\right) .
$$

Adding the momentum balances of the two components leads to

$$
\begin{aligned}
\partial_{\mathrm{t}}(\rho \mathbf{U})+\nabla \cdot(\rho \mathbf{U U})=\Delta \hat{\rho} c g-\nabla p-w_{\mathrm{s}} w_{\mathrm{s}} \cdot \nabla \frac{\rho_{\mathrm{p}} \rho_{\mathrm{f}}}{\rho} \\
+\nabla \cdot\left[\frac{1}{\rho}\left(\frac{\nu_{\mathrm{t}}}{\sigma_{\mathrm{c}}}\right)^{2} \nabla \rho \nabla \rho\right] \\
+\nabla \cdot\left[\left(\nu+\nu_{\mathrm{t}}\right) \nabla(\rho \mathbf{U})+\left(\nu+\nu_{\mathrm{t}}\right)(\nabla(\rho \mathbf{U}))^{\mathrm{T}}\right]
\end{aligned}
$$

with $\mathbf{g}$ the vector of gravitational acceleration. The mixture pressure is defined as $p \equiv p_{\mathrm{f}}+p_{\mathrm{p}}-p_{\text {atm }}$. with the ambient pressure $p_{\text {atm. }}$ subtracted, and the mixture deviatoric stress as $\tau \equiv \tau_{\mathrm{f}}+\tau_{\mathrm{p}}-\frac{\rho_{\mathrm{\rho}} \rho_{\mathrm{p}}}{\rho} w_{\mathrm{s}} w_{\mathrm{s}}$. The viscous part of the stresses appearing in Equation (8) is modelled in terms of the mixture viscosity $\nu$; like the term involving the settling velocity $w_{\mathrm{s}}$, it is usually negligible compared to the turbulent-shear stresses. The next-to-last term in Equation (8) is a consequence of using Favre-averaging for U; the last term predicts turbulent-shear stresses due to density gradients even without velocity gradients.

Equations (5)-(8) have to be complemented by a set of equations determining $k$ and $\epsilon$ so that $\nu_{\text {t }}$ can be calculated. We chose the $k-\epsilon$ model (Launder and Spalding, 1974) as a compromise between accuracy on the one hand and reliability and speed on the other. It consists of transport equations for $k$ and $\epsilon$,

$$
\begin{aligned}
& \partial_{\mathrm{t}}(\rho k)+\nabla \cdot(\mathbf{U} \rho k)=\nabla \cdot\left(\frac{\nu_{\mathrm{t}}}{\sigma_{\mathrm{k}}} \nabla(\rho k)\right) \\
& +\nu_{\mathrm{t}}\left[\nabla(\rho \mathbf{U})+(\nabla(\rho \mathbf{U}))^{\mathrm{T}}\right]:(\nabla \mathbf{U})-\frac{\nu_{\mathrm{t}}}{\sigma_{\mathrm{c}}} \Delta \hat{\rho} \mathbf{g} \cdot \nabla c-\rho \epsilon, \\
& \partial_{\mathrm{t}}(\rho \epsilon)+\nabla \cdot(\mathbf{U} \rho \epsilon)=\nabla \cdot\left(\frac{\nu_{\mathrm{t}}}{\sigma_{\epsilon}} \nabla(\rho \epsilon)\right) \\
& \quad+c_{1 \epsilon} \frac{\epsilon}{k} \nu_{\mathrm{t}}\left[\nabla(\rho \mathbf{U})+(\nabla(\rho \mathbf{U}))^{\mathrm{T}}\right]:(\nabla \tilde{\mathbf{U}}) \\
& \quad-c_{1 \epsilon} c_{3 \epsilon} \frac{\epsilon}{k} \min \left(\frac{\nu_{\mathrm{t}}}{\sigma_{\mathrm{c}}} \Delta \hat{\rho} \mathbf{g} \cdot \nabla c, 0\right)-c_{2 \epsilon} \frac{(\rho \epsilon)^{2}}{\rho k} .
\end{aligned}
$$

(A slightly simplified version of the buoyancy term for $\epsilon$ is used here in view of ambiguities in its formulation.) From a long series of validations, the following set of values is recommended for the model coefficients (Launder and Spalding, 1974):

$$
\begin{aligned}
c_{1 \epsilon} & =1.44, \quad c_{2 \epsilon}=1.92, \quad c_{3 \epsilon} \approx 0.8, \\
\sigma_{k} & =1.0, \quad \sigma_{\epsilon} \approx 1.3 .
\end{aligned}
$$

The boundary conditions at the upper and lateral surfaces of the computational domain depend on model implementation as a free-surface flow or as a boundary-layer flow and will be discussed in section 4 . Those on the bottom surface, describing mass and momentum exchange with the saltation layer, will be developed in section 3 .

\section{THE SALTATION LAYER AND ITS BOUNDARY GONDITIONS}

The currently limited experimental knowledge of the saltation layer, its shallow depth and the hopping motion of particles suggest a somewhat simplified treatment that neglects the air mass balance and uses depth-averaging to avoid explicit calculation of the velocity and density profiles. Figure 1 illustrates our notation and the mass fluxes. Based on experience from sand and snowdrift investigations (Bagnold, 1941; Kikuchi, 1981; Pomeroy and Gray, 1990), the depth of 


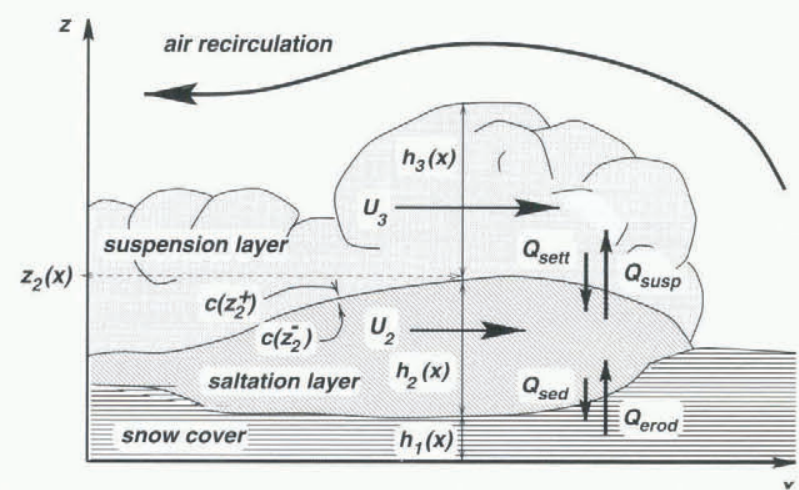

Fig. 1. Schematic view of the structure of a powder-snow avalanche according to Norem (1995). Some quantities relevant to the model described in the text are also indicated. Subscripts 1, 2 and 3 on field variables generally refer to the snow cover, saltation layer and suspension layer, respectively.

the saltation layer, $h_{2}$, is taken to be proportional to the square of the average saltation velocity $U_{2}$,

$$
h_{2}=\beta_{0}^{2} \frac{U_{2}^{2}}{2 g^{\prime}} \text {. }
$$

$g^{\prime}$ is the component of gravity perpendicular to the surface; $g^{\prime}=g \cos \phi$ on an inclined plane but also centrifugal forces due to curvature can be taken into account. From measurements in the field and in wind tunnels, $\beta_{0}=\mathcal{O}(0.1)$.

Neglecting the air, the snow mass balance of the saltation layer is written in terms of the depth-averaged density and velocity as

$\partial_{t}\left(h_{2} \rho_{2}\right)+\nabla_{\|} \cdot\left(h_{2} \rho_{2} \mathbf{U}_{2 \|}\right)=Q_{\text {erod }}-Q_{\text {sed }}-Q_{\text {susp }}+Q_{\text {sett }}$.

(The subscript || on a vector indicates that only the components parallel to the surface are considered.) Apart from advection, the mass can change due to snow entrainment from the ground at a rate $Q_{\text {erod, }}$, snow deposition $\left(Q_{\text {sed }}\right)$, transition of particles from saltation to suspension $\left(Q_{\text {susp }}\right)$, and settling from the suspension layer to the saltation layer $\left(Q_{\text {sett }}\right)$. Similarly, we write the depth-averaged momentum balance as

$$
\begin{aligned}
& \partial_{t}\left(h_{2} \rho_{2} \mathbf{U}_{2 \|}\right)+\nabla_{\|} \cdot\left(s_{\rho \mathrm{UU}} h_{2} \rho_{2} \mathbf{U}_{2 \|} \mathbf{U}_{2 \|}\right) \\
& \quad=h_{2} \rho_{2} \mathbf{g}_{\|}-\nabla_{\|} \cdot\left(s_{\rho z} h_{2}^{2} \rho_{2} g^{\prime}\right)+\hat{\mathbf{n}}_{z} \cdot\left(\tau_{\mathrm{f}, 2}-\tau_{\mathrm{f}, 1}\right)_{\|} \\
& \quad+\left(\beta_{1} Q_{\text {erod }}-\beta_{2} Q_{\text {sed }}-\beta_{3} Q_{\text {susp }}\right) \mathbf{U}_{2 \|}+\gamma_{1} Q_{\text {sett }} \mathbf{U}_{3 \|} .
\end{aligned}
$$

$s_{\rho \mathrm{UU}} \approx 1$ and $s_{\rho z} \approx \frac{1}{2}$ are form factors that arise when the depth-averaged product of fields is expressed as the product of the depth-averaged fields. A more precise determination would require knowledge of the vertical profiles of $\rho$ and $\mathbf{U}$. $\hat{\mathbf{n}}_{z}$ is the unit vector normal to the surface.

The average velocity at which particles hit the ground is modelled as $\beta_{2} \mathbf{U}_{2 \|}$ with $\beta_{2} \gtrsim 1$. $\beta_{3} \gtrsim 1$ is the corresponding factor for particles entering the suspension layer. $\left(\beta_{1} Q_{\text {erod }}\right) /\left(\beta_{2} Q_{\text {sed }}\right)$ with $\beta_{1}<1$ is a measure for the fraction of momentum transmitted from impinging particles to ejected particles; $\beta_{1}=0$ if only aerodynamic entrainment were to take place. Small adjustments would be needed to describe momentum exchange with a dense-flow avalanche. In a fully three-dimensional treatment, $\mathbf{U}_{3 \|}=\beta_{3} \mathbf{U}_{2 \|}$ is the mixture velocity at the bottom of the suspension layer and $\gamma_{1}=1$; in a shallow-water-type approach, $\gamma_{1} \gtrsim 1$ is the ratio of the velocity at the bottom of the suspension layer and the depth-averaged suspension velocity, $U_{3}$.

The particle-settling rate from the suspension layer to the saltation layer is proportional to the settling velocity and the particle concentration at the bottom of the suspension layer:

$$
Q_{\text {sett }}=\hat{\rho}_{\mathrm{p}} c\left(z_{2}^{+}\right) w_{\mathrm{s}} \cos \phi,
$$

where $c\left(z_{2}^{+}\right)$is either obtained from a three-dimensional calculation of the suspension layer or is expressed as $c\left(z_{2}^{+}\right)=\gamma_{2} c_{3}$ in terms of the depth-averaged suspension concentration; the proportionality constant $\gamma_{2}=\mathcal{O}(2-5)$ from laboratory measurements (Keller, 1995) and three-dimensional numerical simulations.

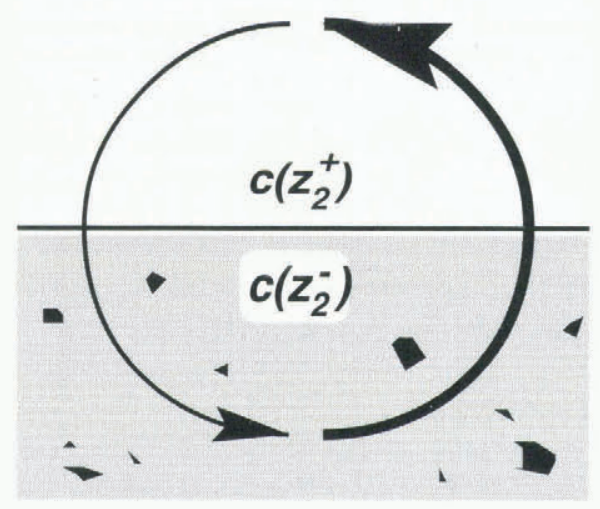

Fig. 2. Schematic diagram of the principal mechanism for particle suspension: turbulent eddies exchange a dense mixture from the saltation layer (particle concentration $c\left(z_{2}^{-}\right)$) with a lower-density mixture from the suspension laver $\left(c\left(z_{2}^{+}\right)\right)$. The average exchange velocity is $\sqrt{\overline{W^{\prime \prime 2}}} \approx \sqrt{k}\left(z_{2}\right) / 3$.

Assuming that the idealized interface between layers is narrower than the size of the dominant eddies contributing to turbulence, the turbulent upward flux through the interface is given by the product of particle concentration just below the interface, $c\left(z_{2}^{-}\right)=\beta_{4} c_{2}$ with $\beta_{4} \lesssim 1$, and the average upward velocity, $\sqrt{\overline{W_{+}^{\prime \prime 2}}}$, and analogously for the turbulent downward flux (Fig. 2). Up to settling effects, $W_{+}^{\prime \prime}+W_{-}^{\prime \prime} \approx 0$ and

$$
\overline{W_{+}^{\prime \prime 2}} \approx \overline{W_{-}^{\prime \prime 2}} \approx \frac{1}{2} \overline{W^{\prime \prime 2}} \approx k / 3
$$

The suspension rate is therefore expressed as

$$
Q_{\text {susp }}=\hat{\rho}_{\mathrm{p}}\left(\beta_{4} c_{2}-c\left(z_{2}^{+}\right)\right) \sqrt{k\left(z_{2}\right) / 3} .
$$

Deviations from isotropic turbulence can be accounted for by changing the coefficient of $k$ in approximation (16). In a shallow-water-type approach one sets $c\left(z_{2}^{+}\right)=\gamma_{2} c_{3}$ and $k\left(z_{2}\right)=\gamma_{3} k_{3}$ in terms of the layer-averaged values; $\gamma_{3}=\mathcal{O}(1)$ from three-dimensional simulations and density-weighted depth-averaging. The particle-sedimentation rate, $Q_{\text {sed, }}$ is equal to the landing rate of particles, i.e. the saltating mass above unit area divided by the average saltation time. Expressing the latter in terms of $U_{2}$, we obtain

$$
Q_{\text {sed }}=\frac{h_{2} c_{2} \hat{\rho}_{\mathrm{p}}}{\Delta t_{\mathrm{salt}}} \approx \frac{\beta_{0}}{4} U_{2} c_{2} \hat{\rho}_{\mathrm{p}} .
$$

Our model for $Q_{\text {erod }}$ is guided by the snowdrift analogy: saltation is maintained mostly through particle ejection at 
impacts. The initial kinetic energy of ejected particles and hence the depth of the saltation layer grows with the average velocity in the saltation layer. The number of ejected particles must then be a slowly varying function of $U_{2}^{2}$; at saltation threshold, on average one particle is ejected per landing particle. Currently, lacking an impact model, we set

$$
Q_{\text {erod }}=\left[1+\alpha\left(\frac{U_{2}^{2}}{U_{\text {thr. }}^{2}}-1\right)\right] Q_{\text {sed }} .
$$

From observations of snowdrift, $U_{\mathrm{thr}} \approx 3-10 \mathrm{~m} \mathrm{~s}^{-1}$, depending on snow conditions. The estimation of $\alpha$ is more critical, because of the exponential growth of particle density in such a "chain reaction". We make use of the observation that a significant saltation layer is usually formed after the DFA has travelled $300-500 \mathrm{~m}$ on a track without cliffs. At a typical relative velocity between air and avalanche surface of $30 \mathrm{~m} \mathrm{~s}^{-1}$, saltation heights are around $1 \mathrm{~m}$, saltation durations are around 1 second and saltation distances are of the order $20-30 \mathrm{~m}$. Starting from the density of snowdrift $\left(c \approx 10^{-5}\right)$, the particle number increases by a factor of $10^{3}-10^{4}$ in $10-25$ jumps. We therefore obtain the rough estimate $\alpha \approx 0.01-0.1$.

Owen (1964) described a self-regulating saltation mechanism that maintains the aerodynamic shear stress on the bed at the minimum value for bed mobility: $\left|\hat{\mathbf{n}}_{z} \tau_{\mathrm{f}, 1 \|}\right|=\rho_{\mathrm{f}} u_{*, \text { thr. }}^{2}$ where $u_{*, \text { thr. }}=0.2-2 \mathrm{~ms}^{-1}$ is the wall-shear velocity below which saltation ceases; this term is therefore negligible except in the very early and very late phases of a PSA. $\hat{\mathbf{n}}_{z} \tau_{\mathrm{f}, 2 \|}$ is the aerodynamic shear stress exerted by the suspension layer, as discussed in section 2 . The saltating snow acts as an effective surface roughness $r$ that grows with the saltation height and density. A firstprinciples determination of $r$ would require precise calculation of saltation trajectories and their effect on the wind field in the saltation layer. In order to obtain an approximation, we assume that: (i) the velocity profile just above the saltation layer is logarithmic, (ii) $\tau_{\mathrm{f}, 2}$ is mainly responsible for accelerating the ejected particles from $\beta_{1} U_{2}$ to $\beta_{2} U_{2}$, and (iii) $Q_{\text {erod }} \approx Q_{\text {sed. Equating the aerodynamic shear stress }}$ to the momentum gain of the particles leads to

$$
\tau_{\mathrm{f}, 2}=\hat{\rho}_{\mathrm{f}} u_{*}^{2} \approx \hat{\rho}_{\mathrm{f}}\left(\frac{\kappa u\left(z_{2}\right)}{\ln \left(h_{2} / r\right)}\right)^{2} \stackrel{!}{=} Q_{\mathrm{sed}} U_{2}\left(\beta_{2}-\beta_{1}\right) .
$$

Inserting Equation (18) and solving for $r$, we have

$$
r=h_{2} \exp \left(-\frac{2 \kappa \beta_{3}}{\sqrt{R \beta_{0}\left(\beta_{2}-\beta_{1}\right) c_{2}}}\right)
$$

where $\kappa \approx 0.4$ is the von Kármán constant. Finally, we obtain

$$
\tau_{\mathrm{f}, 2}=12 \rho_{2} U^{2}\left(z_{2}\right) \frac{\beta_{0}\left(\beta_{2}-\beta_{1}\right)}{4 \beta_{3}^{2}} .
$$

Using the estimated value ranges of $\beta_{0}, \ldots, \beta_{3}$, an effective ground-friction coefficient of $\mathcal{O}\left(10^{-2}\right)$ is obtained.

It is noted that the parameters of the model have a clear physical significance. It appears feasible to obtain better estimates for them by an iterative procedure: Saltation trajectories are computed for an assumed air-velocity profile in the saltation layer and then the effect of the particles on the air

* I thank P. Gauer for communicating his results to me and allowing me to reproduce the pressure map. velocity is accounted for, and so on (Anderson and Haff, 1988). The erosion rate stands apart, because a better model of the impact process is needed for a significant improvement.

\section{IMPLEMENTATIONS AND APPLICATIONS}

Numerical implementation of the model described in the previous sections is currently in progress. For fully three-dimensional simulations, Hermann and others (1994) and Gauer have implemented the suspension-layer model on the basis of a commercial flow solver (CFDS-CFX 4.1; a body-fitted structured grid, finite-volume code with - among other choices - the $k-\epsilon$ turbulence model) and supplemented it with a simple erosion model (Gauer, 1994) that calculates the erosion rate as a function of the turbulent kinetic energy near the ground: the erosion mass flux is given by

$$
Q_{\text {erod }}=\hat{\rho}_{\mathrm{p}} E_{\mathrm{s}} w_{\mathrm{s}}
$$

with

$$
E_{s}= \begin{cases}0, & Z<Z_{\mathrm{c}} \\ 5.2 \times 10^{-5}, & Z \geq Z_{\mathrm{c}}\end{cases}
$$

and the dimensionless shear velocity $Z$ defined by

$$
Z=\frac{\sqrt{R g d_{\mathrm{p}}^{3}}}{\nu} \frac{u_{*}}{w_{\mathrm{s}}} .
$$

$u_{*}$ and $d_{\mathrm{p}}$ are the shear velocity at the snow-cover surface and the average particle diameter, respectively.

The computational grid has to be chosen sufficiently large, so that recirculation of the displaced air is not hindered; no-slip conditions can then be imposed on the top and lateral boundary faces. Air entrainment at the upper PSA surface takes place within the computational domain and is computed by the model. At the bottom surface, the mass flux is prescribed by the entrainment model and the (aerodynamic) wall-shear stress is computed from the turbulence in the flow by means of wall functions (Launder and Spalding, 1974) and the prescribed roughness height.

A recent PSA event at Albristhorn in the Bernese Oberland (Issler and others, 1996) enabled a first test of the implementation with the simple erosion model ${ }^{*}$, because the initial conditions are reasonably well known and the extent of damage to the forest and buildings had been mapped together with the deposition zones of the dense-flow and powder-snow parts. Simulation without erosion and deposition failed, giving very high velocities in the early phases and too-low pressures in the run-out zone. When deposition and the simple erosion model with standard parameter values (Gauer, 1994) (average particle-settling velocity $w_{\mathrm{s}}=0.5 \mathrm{~m} \mathrm{~s}^{-1}$, erosion coefficient $E_{\mathrm{s}}=5.2 \times 10^{-5}$, erosion threshold $Z_{\mathrm{c}}=3.0$ ) were included, a striking correspondence between the simulated pattern of maximum stagnation pressures - defined by $p_{\max }(x, y)=\max _{\mathrm{Z}} \max _{\mathrm{t}}\left\{\frac{1}{2} \rho(x, y, z, t) \mathbf{U}^{2}(x, y, z, t)\right\}-$ and the recorded damage was found (Fig. 3). No tuning of parameters or initial conditions was made and a grid with $80 \times 30 \times 40$ cells was used. Encouraging as it is, the success of this simulation must not be overvalued, because the uncertainties in the initial conditions are considerable and further tests under different conditions are needed to confirm the predictive power of the model.

In the next step of model development, the full two-layer model is being coded in a depth-averaged version that can be applied to problems with relatively simple topography and for 

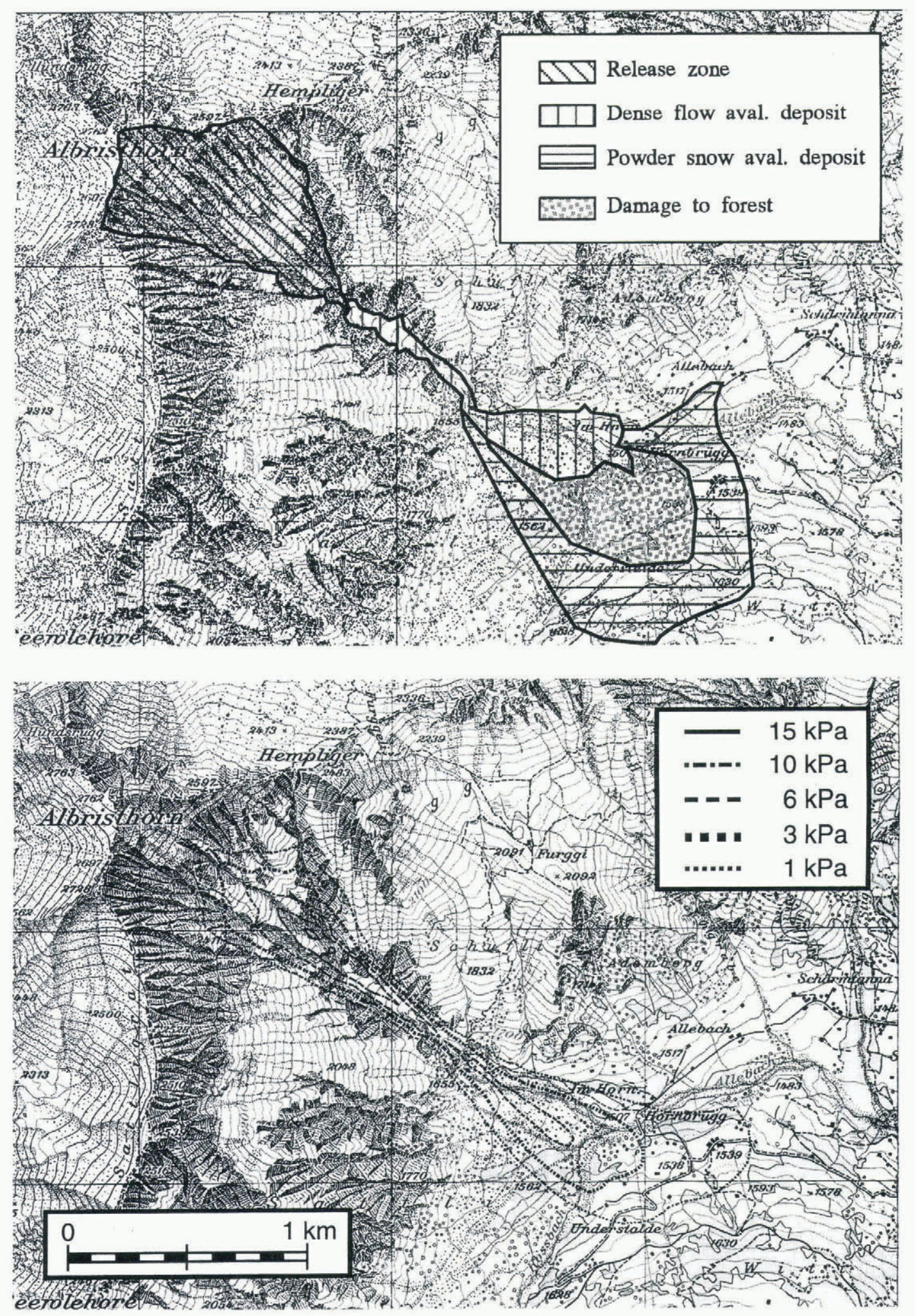

Fig. 3. Powder-snow avalanche near Adelboden (Switzerland). Upper figure: results of a field investigation (from Issler and others, 1996). Lower figure: areal distribution of maximum stagnation pressures from a numerical simulation by Gauer. In the area with pressures in the range 3-5 kPa, the forest was completely destroyed, whereas only occasional trees were broken near but within the $1 \mathrm{kPa}$ line. The basic topographic pixel maps are ${ }^{\mathcal{S}}$ Swiss Federal Office for Cartography; reproduced with permission.

studying the behaviour of the coupled system before the computationally much more demanding three-dimensional version is elaborated. That work will be described elsewhere.

\section{CONCLUSIONS AND OUTLOOK}

The model described here is significantly more complex in its mathematical structure (not so much in numerical effort) than models in use today. A final assessment of what has been gained hereby has to await full numerical implementation and an extended series of validation runs. Nevertheless, a few preliminary conclusions can be drawn:

The two-layered structure of the model takes into account the different flow regimes encountered in PSAs. This is, however, empirical input and not a prediction of the model. 
The approach allows a clear physical description of the boundary conditions at the snow-cover surface and of the interaction between the two layers. Order-of-magnitude estimates can be given for all the model parameters. This is particularly important as long as detailed experimental information is lacking.

Snow entrainment and deposition are critical processes in PSAs. Reasonable results may also be obtained with simpler entrainment models, but they have to be used with great care because the model parameters may depend on avalanche size, e. g. only very few test cases are available for calibration of those simpler models.

In hazard-zoning applications, the choice of initial and boundary conditions is of similar importance as in DFA calculations.

Further model development should address several points, namely (i) a more stringent mathematical formulation of the jump conditions at the layer interfaces, (ii) application to a significant number of well-known cases in order to understand better the dynamic behaviour of this coupled system, (iii) detailed modelling of saltation trajectoriesincluding particle impacts - and their back-reaction on the air flow for a more precise determination of the model coefficients and (iv) coupling to a DFA model to study PSA formation.

\section{ACKNOWLEDGEMENTS}

Practical problems and observations contributed by S. Margreth, M. Schaer and B. Salm have provided strong motivation to the development of this model. I am indebted to H. Norem, F. Hermann, P. Gauer, S. Keller and H. Gubler for many enjoyable discussions on all the important aspects of this work. K. Hutter has pointed out the need for a proper formulation of the jump conditions - still to be fulfilled. Thanks are also due to J. Dent for advice on improving the paper and for his editorial patience. Partial support through a grant from the Swiss Committee for the International Decade for Natural Disaster Reduction (IDNDR) is gratefully acknowledged.

\section{REFERENCES}

Anderson, R. S. and P. K. Haff. 1988. Simulation of eolian saltation. Science, 241, 820-823.

Bagnold, R. A. 1941. The physics of blowing sand and desert dunes. London, Methuen.

Brandstätter, W., F. Hagen, P. Sampl and H. Schaffhauser. 1992. Dreidimensionale Simulation von Staublawinen unter Berücksichtigung realer Geländeformen. Wildbach-und Lawinenverbau, 56 (120), 107-129.

Fukushima, Y. and G. Parker. 1990. Numerical simulation of powder-snow avalanches. 7. Glaciol., 36(123), 229-237.

Gauer, P. 1994. Bewegung einer Staublawine längs eines Berghangs. (Diploma thesis, Technische Hochschule Darmstadt, Germany.)

Hermann, F., D. Issler and S. Keller. 1994. Towards a numerical model of powder snow avalanches. In Wagner, S., E. H. Hirschel, J. Périaux and R. Piva, eds. Second European Computational Fluid Dynamics Conference, September 5-8, 1994, Stuttgart, Germany. Proceedings. Chichester, etc., John Wiley \& Sons, 948-955.

Hermann, F., D. Issler and S. Keller. 1995. Numerical simulations of powder-snow avalanches and laboratory experiments on turbidity currents. In Buisson, L. and G. Brugnot, eds. Pierre Beghin Workshop on Rapid Gravitational Mass Movements, December 6-10, 1993, Grenoble. Proceedings. Grenoble, Éditions CEMAGREF, 137-144.

Hutter, K. 1995. Avalanche dynamics. In Singh, V. P., ed. Hydrology of disasters. Dordrecht, etc., Kluwer Academic Publishers, 317-394.

Issler, D., P. Gauer, M. Schaer and S. Keller. 1996. Staublawinenereignisse im Winter 1995: Seewis (GR), Adelboden (BE) und Col du Pillon (VD). Davos, Eidgenössisches Institut für Schnee- und Lawinenforschung. (Internal Report 694.

Keller, S. 1995. Physikalische Simulation von Staublawinen - Experimente zur Dynamik im dreidimensionalen Auslauf. (Ph.D. thesis, Eidgenössische Technische Hochschule Zürich.)

Kikuchi, T. 1981. A wind tunnel study of the aerodynamic roughness associated with drifting snow. Cold Reg. Sci. Technol., 5(2), 107-118.

Launder, B. E. and D. B. Spalding. 1974. The numerical computation of turbulent flow. Comput. Methods Appl. Mech. Eng., 3, $269-289$.

Naaim, M. 1995. Modélisation numérique des avalanches aérosols. Houille Blanche, 50(5-6), 56-62.

Nishimura, K., N. Maeno, K. Kawada and K. Izumi. 1993. Structures of snow cloud in dry-snow avalanches. Ann. Glaciol., 18, 173-178.

Norem, H. 1995. Shear stresses and boundary layers in snow avalanches. Oslo, Norges Geotekniske Institutt. (NGI Rapport 581240-3.)

Norem, H., T. Kvisterøy and B.D. Evensen. 1985. Measurement of avalanche speeds and forces: instrumentation and preliminary results of the Ryggfonn Project. Ann. Glaciol., 6, 19-22.

Owen, P. R. 1964. Saltation of uniform grains in air. 7. Fluid Mech., 20(2), $225-242$.

Pomeroy, J.W. and D. M. Gray. 1990. Saltation of snow. Water Resour. Res., 26 $(7), 1583-1594$.

Rapin, F. 1995. French theory for the snow avalanches with aerosol. In Brugnot, G., ed. Actes de l'Université Européenne d'Été sur les risques naturels - neiges et avalanches, $14-25$ septembre 1992, Chamonix, France. Grenoble, Éditions CEMAGREF, 163-172.

Schaerer, P. A. and A. A. Salway. 1980. Seismic and impact-pressure monitoring of flowing avalanches. F. Glaciol., 26(94), 179-187.

Scheiwiller, T. and K. Hutter. 1982. Lawinendynamik: Übersicht über Experimente und theoretische Modelle von Fliess- und Staublawinen. Eidg. Tech. Hochschule, Zürich.Versuchsanst. Wasserbau, Hydrol. Glaziol. Mitt. 58. 